\title{
Rho-GEF Trio regulates osteosarcoma progression and osteogenic differentiation through Rac1 and RhoA
}

\author{
Junyi Wang ${ }^{1,3}$, Lichan Yuan ${ }^{1,3}$, Xiaohong $\mathrm{Xu}^{1}$, Zhongyin Zhang ${ }^{1}$, Yuhuan $\mathrm{Ma}^{2}$, Leilei Hong ${ }^{1}$ and Junqing Ma (iD ${ }^{1 凶}$
}

(c) The Author(s) 2021

Osteosarcoma (OS) is the most common primary bone tumor. Its high mortality rate and metastasis rate seriously threaten human health. Currently, the treatment has reached a plateau, hence we urgently need to explore new therapeutic directions. In this paper, we found that Trio was highly expressed in osteosarcoma than normal tissues and promoted the proliferation, migration, and invasion of osteosarcoma cells. Furthermore, Trio inhibited osteosarcoma cells' osteogenic differentiation in vitro and accelerated the growth of osteosarcoma in vivo. Given Trio contains two GEF domains, which have been reported as the regulators of RhoGTPases, we further discovered that Trio could regulate osteosarcoma progression and osteogenic differentiation through activating RhoGTPases. In summary, all our preliminary results showed that Trio could be a potential target and prognostic marker of osteosarcoma.

Cell Death and Disease (2021)12:1148; https://doi.org/10.1038/s41419-021-04448-3

\section{INTRODUCTION}

Osteosarcoma (OS), as one of the common malignant bone tumors, is derived from osteoblasts and mainly affects adolescence and childhood $[1,2]$. It mostly occurs in the long bones, additionally $6-10 \%$ in the craniofacial bones, causing jawbones lesions and facial deformities [1,3]. With the aid of neoadjuvant and adjuvant chemotherapy, the 5-year survival rate of localized OS has increased to $70 \%$ since the 1970 s $[4,5]$. Currently, new molecular imaging methods, improved surgical techniques, and improved implant design provide convenience for precision surgery [6-8]. Of note, the 5-year survival rate deteriorates to $20 \%$ for metastatic patients $[4,5]$. Some studies put forward that the bone microenvironment, such as mesenchymal stem cells, hypoxia, and chemokines, may be used as the potential target for lung metastasis $[9,10]$. Besides, immunotherapy has proven to be a promising therapeutic strategy which intended to block molecular pathways associated with proliferation and metastasis of OS [7, 11]. Even with multiple advanced treatment therapies, effective therapeutic targets or diagnostic markers for OS have not yet been determined. No significant progress has been made in the treatment of OS, which makes its treatment more intractable and challenging. Therefore, further research is needed for progressive strategies and novel treatment targets of OS.

RhoGTPases belong to the Ras superfamily of GTPases, among which RhoA, Rac1, and Cdc42 are the three most canonical members [12]. RhoGTPases are implicated in a series of cellular events, including cell polarity, adhesion, motility, and cycle progression by regulating actin cytoskeleton rearrangements and microtubule dynamics. Consequently, Rho GTPases have active roles in malignant transformation, immunological diseases, neurological abnormalities, and cardiovascular diseases [12, 13]. It has been established extensively that RhoGTPases switch back and forth between an active GTP-bound state and an inactive GDP-bound state. There are three canonical regulators that can affect this switching regulation of GDP/GTP, including Rho family guanylate exchange factors (GEFs) that accelerate the conversion of GDP to GTP, rendering the GTPases active; GTPases activating proteins (GAPs) that promote the hydrolysis of GTP and inactivate GTPases; GDP dissociation inhibitors (GDIs) that sequester the inactive GDP-bound GTPases in the cytoplasm and inhibit them from being activated by GEFs [12-14].

Triple functional domain (Trio), which is the member of the DBL family, harbors three domains with enzymatic activity, two GEFs, and one serine kinase domain. The GEFD1 domain can activate Rac1 as well as RhoG, while the GEFD2 domain specifically activates RhoA. In addition, the activated RhoG can further activate Cdc42 [15]. The Trio is well-known for its central player in neuronal development [15-17]. Moreover, Trio also plays a prominent role in fetal skeletal muscle formation and embryonic development [18]. In recent years, a mounting number of studies have demonstrated that Trio is significantly increased in different types of tumors, including bladder cancer, breast cancer, lung cancer, oral cancer, glioblastoma, and soft tissue sarcoma $[15,19-21]$. However, the regulatory mechanism responsible for the development of tumors has not yet been fully elucidated, and little is known either about the roles of Trio in OS. Currently, a number of studies have confirmed that RhoGTPases or their downstream molecules are instrumental in the invasion and metastasis of OS cells [14, 22-29]. Accordingly, we put forward the hypothesis that Trio could regulate OS cells migration and invasion through RhoGTPases.

We previously showed that Trio had important functions both in regulating tooth root development and osteoclast differentiation $[30,31]$. In this study, we explored the influences of Trio on OS cells and the potential biochemical mechanism regulated by Trio.

\footnotetext{
${ }^{1}$ Jiangsu Key Laboratory of Oral Diseases, Nanjing Medical University, 140 Hanzhong Road, 210029 Nanjing, China. ${ }^{2}$ Nanjing Foreign Language School, 210008 Nanjing, Jiangsu,

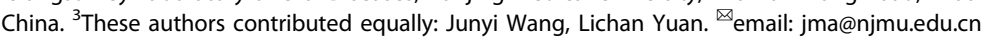

Edited by Professor Stephen Tait
} 
In my view, this study is beneficial in providing new directions for the treatment and prognosis of OS.

\section{MATERIALS AND METHODS Cell culture}

Normal human osteoblast cell line hFOB1.19, as well as human OS cell line U2OS, were purchased from GeneChem (Shanghai, China). Human OS cell line 143B was obtained from FuHeng Cell Center (Shanghai, China). U2OS and 143B were cultured in Dulbecco's modified Eagle's medium (DMEM) supplemented with 10\% FBS. hFOB1.19 was cultured in F12/ DMEM supplemented with $15 \%$ FBS. All of the above cell lines were cultured in an incubator containing $5 \% \mathrm{CO}_{2}$ at $37^{\circ} \mathrm{C}$.

\section{Clinical samples}

OS tissue samples and their matched normal samples from 10 OS patients were collected from Jiangsu Provincial Stomatological Hospital and informed consent was obtained from all patients. The Ethical Committee at the Stomatological School in Nanjing Medical University approved this study.

\section{Cell migration and invasion assays}

To assess the migratory and invasive ability of OS cells, we conducted the transwell assay with a chamber ( $8 \mu \mathrm{m}$; Corning; for the migration assay) or a chamber precoated with Matrigel (Corning, 356234; for the invasion assay). Briefly, U2OS and $143 \mathrm{~B}$ cells $\left(5 \times 10^{4}\right.$ for the migration assay or $10^{6}$ for the invasion assay) were seeded on the upper chambers of 24-well plates. Then the $500 \mu \mathrm{L}$ medium supplemented with $10 \%$ FBS was added in the lower chamber as a chemoattractant. After $24 \mathrm{~h}$ incubation, the cells that had migrated or invaded into the lower chambers were fixed with $4 \%$ paraformaldehyde (PFA) for $30 \mathrm{~m}$, then stained with crystal violet for another $15 \mathrm{~m}$ and finally observed by microscopy (Leica Microsystems, Ontario, Canada) with $\times 200$ magnification. Three fields were randomly selected to count cell numbers.

\section{Wound healing assay}

U2OS and 143B cells were seeded at a density of $5 \times 10^{5}$ cells/ well into sixwell plates and cultured until a $90-100 \%$ confluence was formed. We then scratched the cells using $200 \mu \mathrm{L}$ pipette tips. Floating cells were washed once with PBS, and photos were taken by a light microscope (DMIL LED; Leica Microsystems $\mathrm{GmbH}$ ) at 0,24 , and $48 \mathrm{~h}$ with $\times 100$ magnification.

\section{CCK-8 assay}

Cell-counting kit-8 (Dojindo, Japan) was conducted in order to evaluate the cell proliferation ability. Cells $\left(10^{3}\right)$ were seeded in 96 -well plates and the medium was replaced with $90 \mu \mathrm{L}$ fresh medium added with $10 \mu \mathrm{L} \mathrm{CCK}-8$ reagent at the scheduled time points $(0,24,48,72$, and $96 \mathrm{~h})$. Following $2 \mathrm{~h}$ incubation, the absorbance was measured by the Microplate reader at an optical density of $450 \mathrm{~nm}$.

\section{Colony formation assay}

U2OS and 143B cells $\left(10^{3}\right)$ were seeded in six-well plates and cultured for 10 days to form colonies. Then, the cells were washed twice with PBS, fixed with $4 \%$ PFA, and stained with crystal violet for $15 \mathrm{~m}$.

\section{Flow cytometry}

To measure apoptosis, cells were trypsinized, washed with PBS, filtered with filter membranes, and stained with Annexin V-FITC/PI. Cell apoptosis was analyzed by a flow cytometer (Becton-Dickinson, SanJose, CA, USA).

\section{Small interfering RNA (siRNA) transfection}

Three kinds of siRNAs that targeted Trio and negative control siRNA were purchased from GenePharma (Suzhou, China). The siRNAs sequences are included in Table 1.

Lipofectamine 2000 (Invitrogen, CA) was used to transfect U2OS and $143 \mathrm{~B}$ cells with siRNAs according to the manufacturer's instructions when grew to a $50-70 \%$ confluence. After transfection for $48 \mathrm{~h}$, cells were collected and prepared for further assays.

\section{Lentiviral transfection}

A lentivirus targeting Trio and a negative control lentivirus were purchased from GenePharma (Suzhou, China). The shRNA Trio sequences were as follows:
Table 1. List of siRNAs sequences.

\begin{tabular}{|lll} 
& Forward $\left(\mathbf{5}^{\prime} \mathbf{-} \mathbf{3}^{\prime}\right)$ & Reverse $\left(\mathbf{5}^{\prime} \mathbf{-} \mathbf{3}^{\prime}\right.$ ) \\
\hline 1\# & CCGGCAAACUUGGAUCCAUTT & AUGGAUCCAAGUUUGCCGGTT \\
\hline 2\# & GCAGACGUCUUCCUGAAAUTT & AUUUCAGGAAGACGUCUGCTT \\
\hline $3 \#$ & CCUUCAACCCUUCGGAUAATT & UUAUCCGAAGGGUUGAAGGTT \\
\hline
\end{tabular}

shTrio-1: 5'-GCAGACGTCTTCCTGAAAT-3'; shTrio-2: 5'-CCTTCAACCCTTCGGATAA-3'.

After $72 \mathrm{~h}$ infection with lentivirus, stably transfected cells were selected using puromycin $(2 \mu \mathrm{g} / \mathrm{ml})$ for 2 weeks. The infection efficiency was observed in a form of GFP by fluorescence microscopy (Leica Microsystems, Ontario, Canada) and verified by western blot.

\section{IHC and H\&E staining assay}

The paraffin-embedded samples were sectioned ( $3 \mu \mathrm{m}$ thickness) for further immunohistochemistry and H\&E assays. For immunohistochemistry, the tissue sections were firstly dewaxed and boiled in sodium citrate buffer solution for $10 \mathrm{~min}$ to retrieve antigens, subsequently treated with $3 \% \mathrm{H}_{2} \mathrm{O}_{2}$ for $30 \mathrm{~m}$ and blocked with normal goat serum for $30 \mathrm{~m}$ at $37^{\circ} \mathrm{C}$. Finally, sections were incubated with the primary antibody at $4{ }^{\circ} \mathrm{C}$ overnight. The next day, sections were washed with PBS, then treated with a secondary HRP-conjugated antibody and dyed using the DAB developing kit. Eventually, cell nuclei were stained with hematoxylin. For $\mathrm{H} \& \mathrm{E}$, the dewaxed sections were stained with hematoxylin for cell nuclei and eosin for cytoplasm.

The following antibodies were used: Trio (Santa Cruz, sc-28564), E-Cadherin (Cell Signaling Technology, \#3195), N-Cadherin (Cell Signaling Technology, \#13116), Vimentin (Cell Signaling Technology, \#5741), RUNX2 (Abcam, \#ab76956), OSX (Abcam, \#ab22552), OPN (Abcam, \#ab63856).

\section{Western blotting analysis}

Cell proteins were extracted as previously described [32]. Equal levels of proteins were loaded onto 10\% SDS-PAGE gel for electrophoresis $(6 \%$ for Trio). After the electrophoresis, proteins were transferred to PVDF membranes on ice and immediately blocked with 5\% defatted milk (5\% BSA for phosphorylated protein) for $2 \mathrm{~h}$ at room temperature, finally incubated with primary antibodies at $4{ }^{\circ} \mathrm{C}$ overnight. On the second day, the membranes were washed in TBST three times, then incubated with secondary antibodies for $1 \mathrm{~h}$ at room temperature and washed with TBST another three times. Eventually, the blots were detected by an ECL chemiluminescence system. Quantitative analysis of images was conducted using ImageJ v.1.52 software. The following antibodies were used: Trio (Abcam, \#ab194365), E-Cadherin (Cell Signaling Technology, \#3195), N-Cadherin (Cell Signaling Technology, \#13116), Vimentin (Cell Signaling Technology, \#5741), Snail (Cell Signaling Technology, \#3879), RUNX2 (Abcam, \#ab76956), OSX (Abcam, \#ab22552), OPN (Abcam, \#ab63856), OCN (Abcam, \#ab93876), p38 (Cell Signaling Technology, \#9212), p-p38 (Cell Signaling Technology, \#9211), JNK (Cell Signaling Technology, \#9252), p-JNK (Cell Signaling Technology, \#4668,), ERK (Cell Signaling Technology, \#4695), p-ERK (Cell Signaling Technology, \#4370), GAPDH (Bioworld, \#AP0063).

\section{RNA isolation and quantitative real-time PCR}

Total RNA was extracted by an RNA isolation kit (BioTeke, Beijing, China) and cDNAs were synthesized by HiScript ${ }^{\circ}$ RT SuperMix for qPCR (Vazyme, Nanjing, China) according to the manufacturer's instructions. Real-time quantitative PCR was carried out using the ChamQ SYBR qPCR Master Mix (Vazyme, Nanjing, China) on QuantStudio7 (ABI). The relative RNA expression levels were analyzed by the formula of $2^{-\triangle \Delta C t}$. The following primers used are listed in Table 2.

\section{Immunofluorescence assay}

After transfection with siRNA control or siRNA Trio for $48 \mathrm{~h}, \mathrm{U} 2 \mathrm{OS}$ and 143B cells were firstly fixed with $4 \%$ PFA for $15 \mathrm{~min}$ at room temperature, then blocked with normal goat serum for $30 \mathrm{~min}$ at $37^{\circ} \mathrm{C}$ and finally incubated with primary antibodies overnight at $4{ }^{\circ} \mathrm{C}$. On the second day, the cells were washed with PBS, followed by incubation with Alexa488-conjugated secondary antibodies for $1 \mathrm{~h}$ at $37^{\circ} \mathrm{C}$, then washed again with PBS and subsequently stained with DAPI for 2 min. For cytoskeleton staining, the fixed cells were treated with phalloidin (Cytoskeleton) for $30 \mathrm{~min}$ at $37^{\circ} \mathrm{C}$. The cells were observed using the fluorescence microscope (Leica Microsystems, Ontario, Canada). 
Table 2. The primer sequences used for the qRT-PCR.

\begin{tabular}{ll}
\hline Gene & Forward \\
\hline Trio & AGGCCGAAAAGTATATGAGCAAC \\
\hline E-Cadherin & TCTGCTGCTCTTGCTGTTTC \\
\hline N-Cadherin & ATCATTGCCATCCTGCTC \\
Vimentin & GAAGAGAACTTTGCCGTTG \\
\hline Snail & ACATCCGAAGCCACACG \\
MMP9 & ACGCAGACATCGTCATCC \\
\hline RUNX2 & AGGCAGTTCCCAAGCATTTCATCC \\
\hline COL1A1 & AAAGATGGACTCAACGGTCTC \\
\hline OPN & TCACACATGGAAAGCGAGGAGTTG \\
\hline OSX & CGGCAAGAGGTTCACTCGTTCG \\
\hline OCN & CTACCTGTATCAATGGCTGGG \\
\hline ALP & CTTCATAGAAGGGGAGCTGTAC \\
\hline GAPDH & GAAGGTGAAGGTCGGAGTC \\
\hline
\end{tabular}

Reverse
GTCAAGGAGCGACTTCCCAT
CTCTTCTCCGCCTCCTTCTT
TCCTCCACCTTCTTCATCA
GAAGGTGACGAGCCATTT
TGGGGACAGGAGAAGGG
CCAGGGACCACAACTCG
TGGCAGGTAGGTGTGGTAGTGAG
CATCGTGAGCCTTCTCTTGAG
ACTGTCCTTCCCACGGCTGTC
TGGAGCAGAGCAGGCAGGTG
GGATTGAGCTCACACACCT
GATACAGAGTGACCGTGTCAT
GAGATGGTGATGGGATTTC

\section{Rho GTPase activity assay}

Rac1 and RhoA activity were assessed using Rac1 Activation Assay Biochem Kit (Cytoskeleton, \#BK035) and Rho Activation Assay Biochem Kit (Cytoskeleton, \#BK036), respectively, following the manufacturer's instructions. In brief, Rac1-GTP and RhoA-GTP were pulled down from total proteins using the matching beads (PAK-PBD beads for Rac1 and Rhotekin RBD beads for RhoA), then the total and active Rho GTPase was detected by Western blot with antiRac1 antibody (Cytoskeleton) and anti-RhoA antibody (Cytoskeleton).

\section{In vivo assay}

$5 \times 10^{6}$ U2OS cells transfected with shCtrl or shTrio stably were inoculated subcutaneously in the flanks of BALB/C nude mice (male, 4 weeks old, $n=4$ each group). Tumor size was measured every one week by vernier caliper through the following formula: volume $\left(\mathrm{mm}^{3}\right)=a b^{2} / 2$ (" $a$ " is the smallest diameter, " $b$ " is the largest diameter). Seven weeks after inoculation, the IVIS Spectrum Imaging System (PerkinElmer) was used to capture the GFP signal by taking photographs. Finally, mice were euthanized and tumors were harvested, weighed, photographed, and fixed in 4\% PFA for future assays.

\section{Alkaline phosphatase (ALP) assay and Alizarin red S (ARS) staining}

U2OS and 143B cells were induced for osteogenic differentiation in a normal medium supplemented with $10 \mathrm{mM} \beta$-glycerophosphate (Sigma, St. Louis, USA), $50 \mathrm{mg} / \mathrm{ml}$ ascorbate phosphate (Sigma), and $10 \mathrm{nM}$ dexamethasone (Sigma). After 5 days of induction, cells were fixed with 4\% PFA, washed with PBS, and stained using BCIP/NBT ALP Color Development Kit (Beyotime Institute of Biotechnology, Shanghai, China) following the manufacturer's protocols. After 14 days, Alizarin red (Beyotime Institute of Biotechnology, Shanghai, China) was used to stain cells. Photos were taken using a scanner and light microscope (DMIL LED; Leica Microsystems $\mathrm{GmbH}$ ) at $\times 200$ magnification.

\section{Statistical analysis}

All experiments were conducted in triplicate. Statistical analysis was analyzed using a Student's $t$-test with GraphPad Prism 8.4.0 (GraphPad Software, La Jolla, CA, USA) and data were expressed as the mean \pm SD. $p<$ 0.05 and $p<0.01$ are marked with ${ }^{*}$ and ${ }^{* *}$, respectively.

\section{RESULTS}

\section{Expression of Trio is elevated in OS}

In order to ascertain the role of Trio in OS, we firstly analyzed the data from the CCLE database and found that the mRNA level of Trio was relatively up-regulated in OS (Fig. 1A). In addition, the data from the TCGA database showed that Trio was elevated in sarcoma than normal tissues (Fig. 1B), and the prognosis of sarcoma patients with high Trio levels was worse than that with low-level ones (Fig. 1C, D). Similarly, it was suggested that Trio was associated with a poor prognosis of OS from the TARGET OS project database (Fig. 1E, F). Based on the information above, we speculated that Trio was upregulated in OS. To test our hypothesis, we performed western blot and real-time PCR to examine the differential expression of Trio in osteoblast hFOB1.19 and OS cell lines (U2OS, 143B). As a result, Trio was significantly elevated in OS cells compared with osteoblast cells both on the transcriptional level and the protein level (Fig. 1G-l). Moreover, we also performed immunohistochemical staining to further prove that Trio was highly expressed in OS (Fig. 1J). These results suggested that Trio may play a critical role in the occurrence and development of OS.

\section{Trio knockdown inhibits the proliferation of OS cells}

To gain further insight into the involvement of Trio in OS, we applied three siRNA targeting Trio (from GenePharma). After $48 \mathrm{~h}$ transfection, the silencing efficiency was detected by realtime PCR (Fig. 2A). Then the most efficient one (siRNA Trio 2) was selected and verified by western blot (Fig. 2B, C) for the subsequent assays. Firstly, we sought to examine whether Trio affected the proliferation and apoptosis of OS cells. The outcomes of CCK-8 assays demonstrated that the proliferation was impeded after Trio silencing (Fig. 2D). Meanwhile, in order to obtain a more stable and long-term knock-down level for following related experiments, U2OS and $143 \mathrm{~B}$ cells were transfected with short hairpin RNA (shRNA) targeting Trio (shTrio-1/shTrio-2) and selected by adding puromycin $(2 \mu \mathrm{g} / \mathrm{ml})$ for 2 weeks. The fluorescence was observed after $72 \mathrm{~h}$ of transfection (Figs. 2E and S1A) and knock-down levels were detected by western blot (Figs. 2F, G, S1B), which showed that shTrio-2 could not effectively knock down Trio on the protein level. Similarly, the colony formation assays demonstrated that shTrio-1-mediated Trio deletion attenuated the proliferation of OS cells, but shTrio-2 did not significantly affect proliferation capacity (Figs. $2 \mathrm{H}, \mathrm{I}$ and S2). For this reason, we selected shTrio-1 lentivirus for the following assays. There was no significant difference in apoptosis between the shCtrl group and shTrio group through flow cytometry (Fig. 2J).

Trio knockdown inhibits OS cell migration and invasion, and affects actin cytoskeleton rearrangements

It has been established that migration and invasion are indispensable steps in the initiation of tumor metastasis. To further elucidate the role of Trio in this process, we carried out a series of experiments. Wound healing assays showed that Trio silenced cells exhibited an obvious decrease in the wound healing rate (Fig. 3A, B). In addition, transwell assays were conducted to further explore the effects of Trio on the migration and invasion potentials of U2OS and 143B cells. The results reflected that Trio silencing led to an evident decrease in both (Fig. 3C, D). Actin cytoskeleton rearrangement has been implicated in the development of tumors underlining its importance in cell motility. 
A

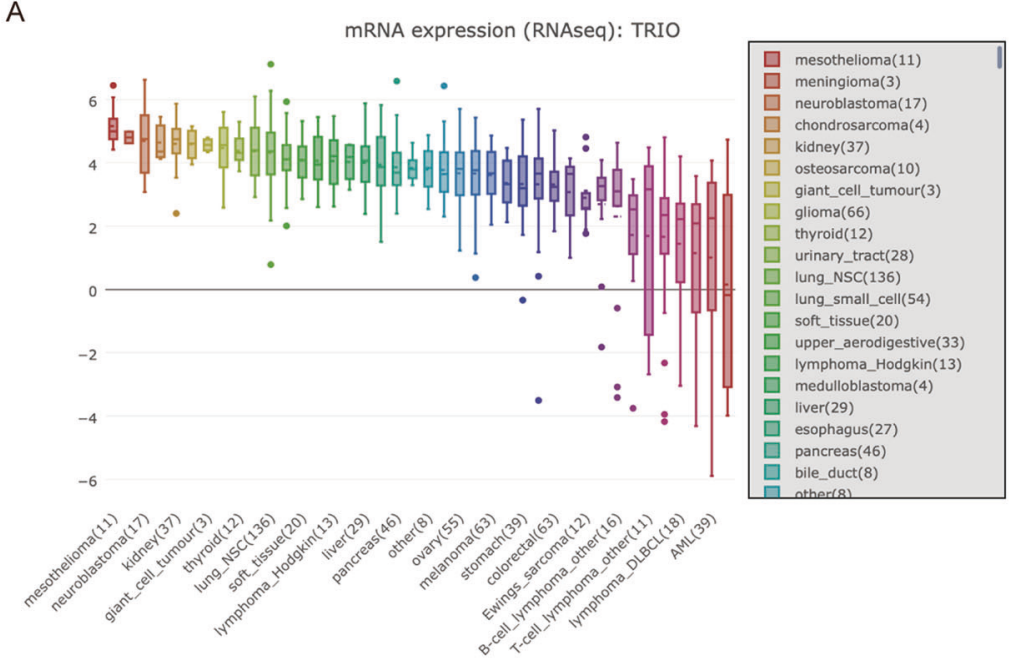

C

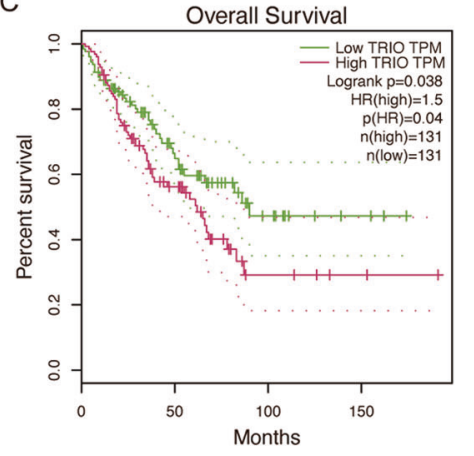

F

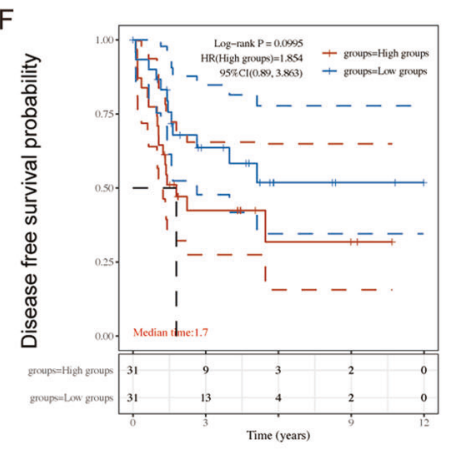

D

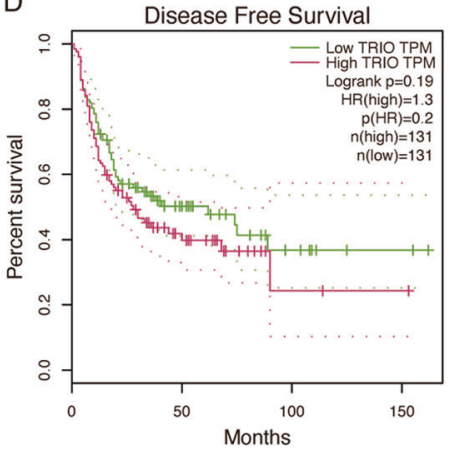

G

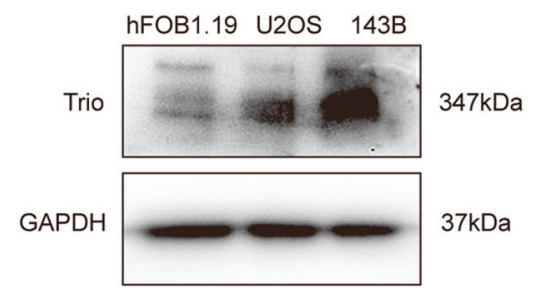

B

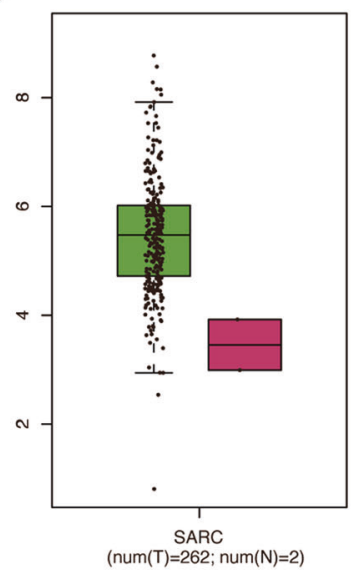

E

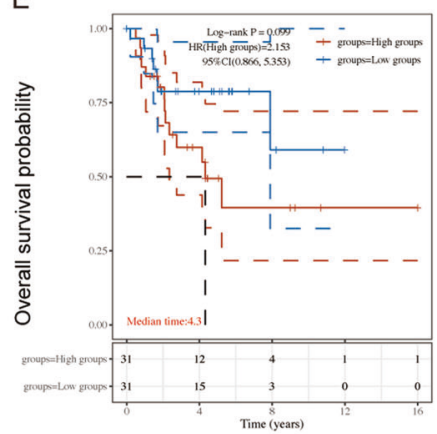

$\mathrm{H}$

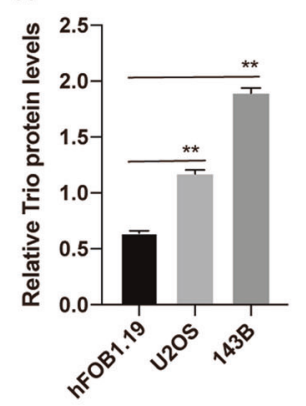

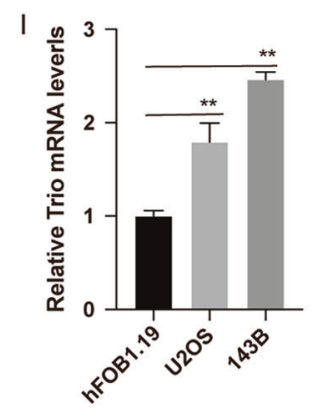

$\mathrm{J}$
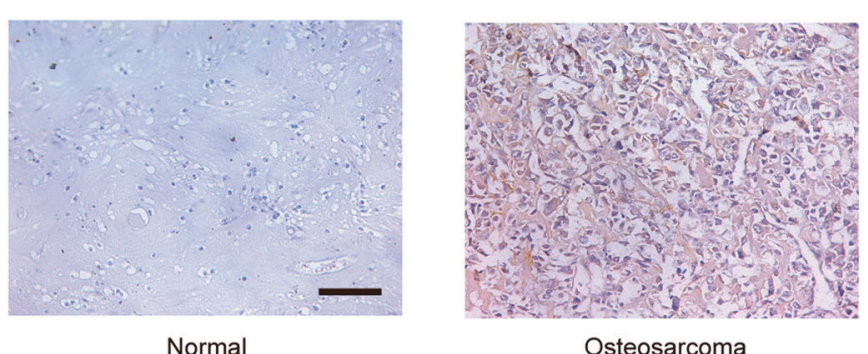

Osteosarcoma

Fig. 1 Expression of Trio is elevated in osteosarcoma. A The Trio mRNA levels in different cancer type cell lines from the CCLE database. B The expression levels of Trio in sarcoma and normal control tissues were achieved from the TCGA database. C and D Kaplan-Meier curves show the disease-free survival and the overall survival of patients with sarcoma (TCGA database) in terms of Trio gene expression. $\mathbf{E}$ and $\mathbf{F}$ Kaplan-Meier curves show the disease-free survival and the overall survival of patients with osteosarcoma (TARGET database) in terms of Trio gene expression. G-I The expression levels of Trio in hFOB1.19, U2OS,143B were measured by Western blot and qRT-PCR. J The expression levels of Trio in osteosarcoma and normal control tissues were detected by IHC. Representative images are shown (magnification at $\times 200$ ). Data are shown as the mean \pm SD. ${ }^{*} p<0.05,{ }^{* *} p<0.01$. Scale bars: $100 \mu \mathrm{m}$. 
A

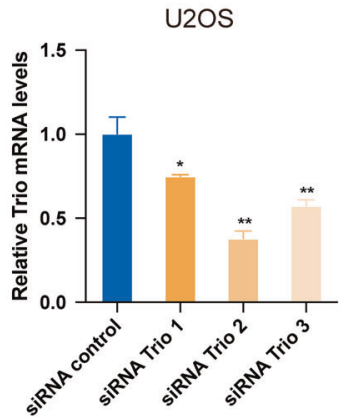

C

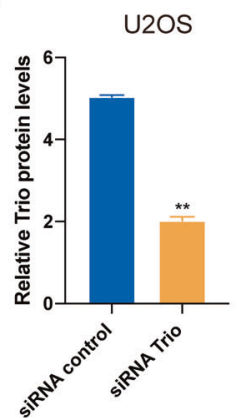

E

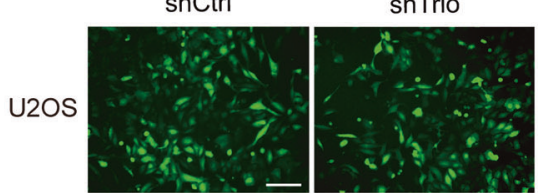

143B

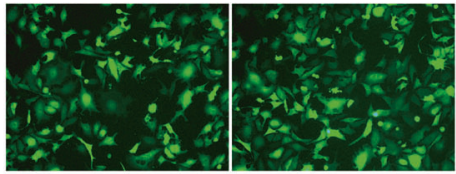

H

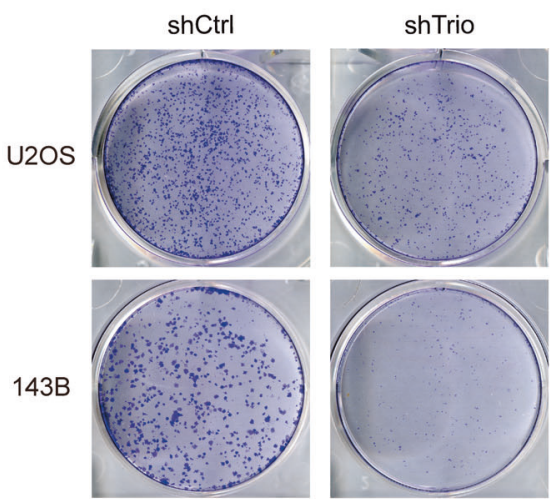

143B

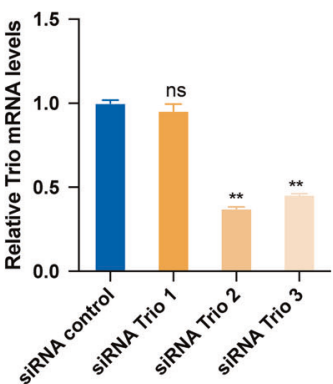

D
B

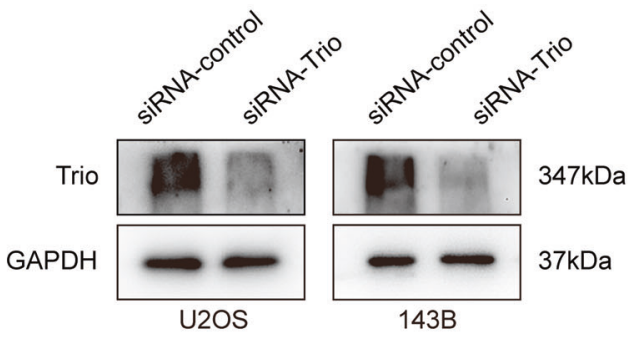

U2OS
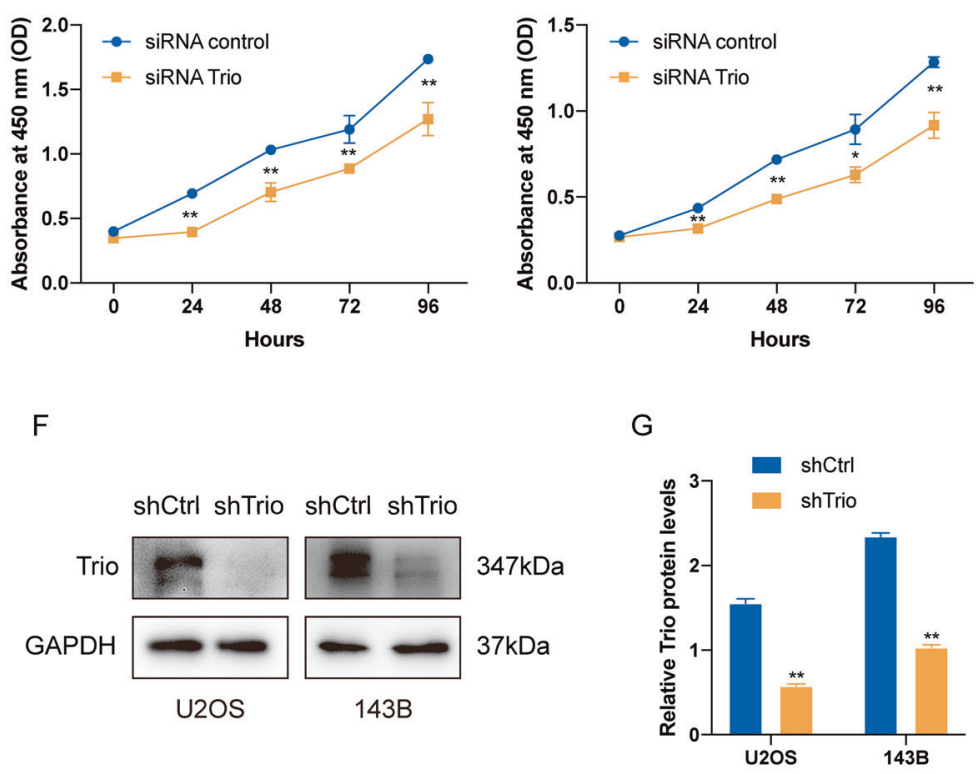

J

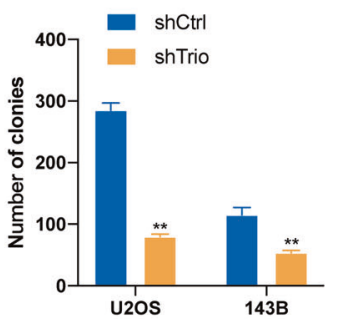

Fig. 2 Trio knockdown inhibits the proliferation of osteosarcoma cells. A-C Efficiency of siRNA-mediated Trio knockdown in U2OS and 143B cells was measured by qRT-PCR and Western blot. D SiRNA-mediated Trio knockdown suppressed OS cell growth, as determined by the CCK-8 assay. E Efficiency of shRNA-mediated Trio knockdown in U2OS and 143B cells was detected by GFP. F and G Efficiency of shRNA-mediated Trio knockdown in U2OS and 143B cells was measured by qRT-PCR and Western blot. $\mathbf{H}$ and I Trio knockdown suppressed the colony formation of U2OS and 143B cells. J Cell apoptosis was measured by cytometry. Data are shown as the mean \pm SD. ${ }^{*} p<0.05,{ }^{* *} p<0.01$. Scale bars: $100 \mu \mathrm{m}$.

Accordingly, we examined whether Trio silencing altered the cytoskeleton by performing immunofluorescence assay using FITC-Phalloidin. As anticipated, the siRNA-control group had sufficient stress fibers, while the actin filament integrity was weakened in cells transfected with siRNA-Trio (Fig. 3E). Taken together, these results above suggested that Trio induced the migration and invasion potentials of OS cells.
Trio is involved in epithelial-mesenchymal transition (EMT) It is well known that EMT is a crucial biological process in tumor progression, in which cells transform from a polarized, closely contacted form to a form that loses polarization and becomes more motorial [33]. In view of this, it was postulated that Trio may serve as an important role in this process. As shown in Fig. $4 \mathrm{~A}, \mathrm{C}$, the epithelial marker (E-cadherin) mRNA, and protein 
A
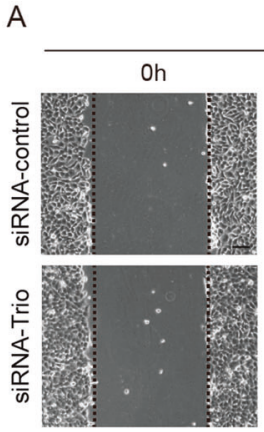

205
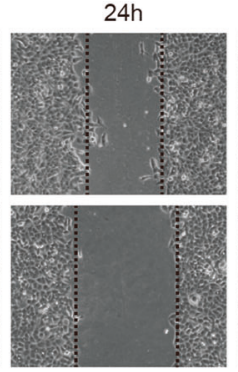

$48 \mathrm{~h}$
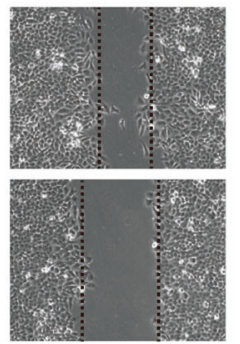
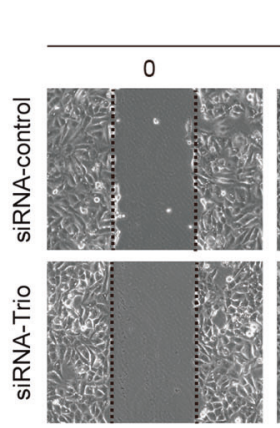
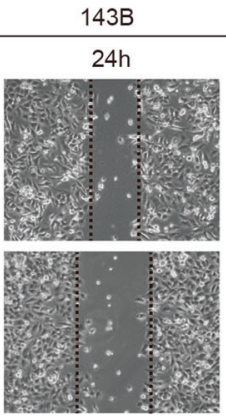
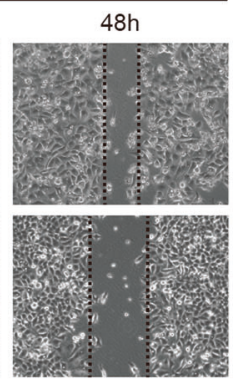

B
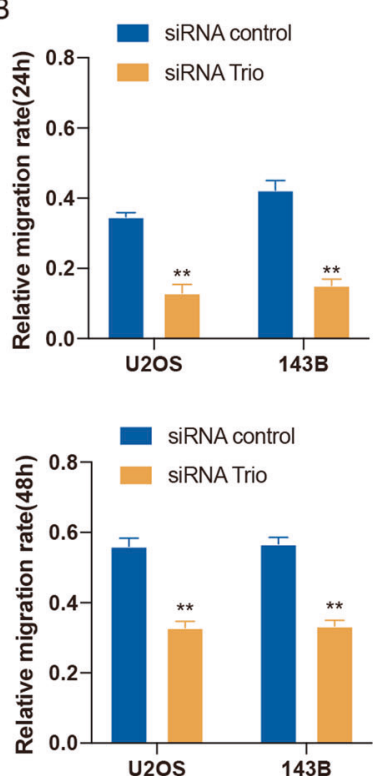

E

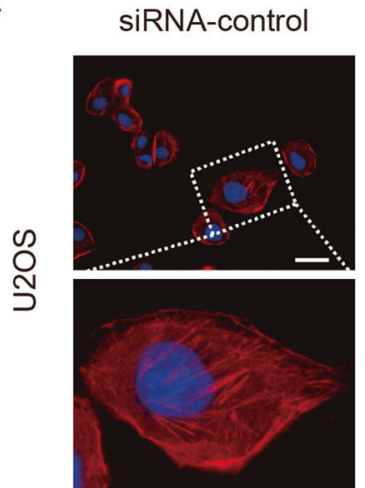

C

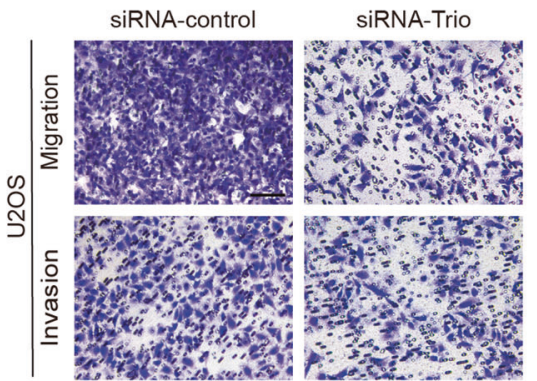

D

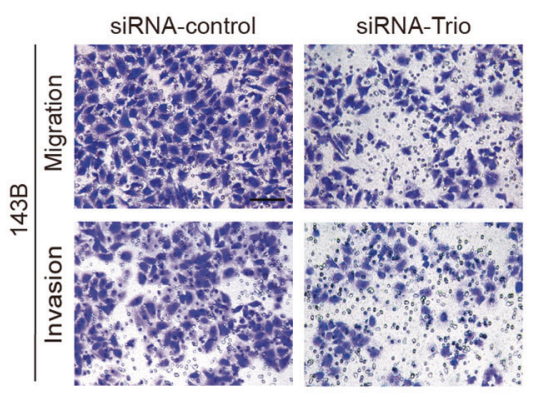

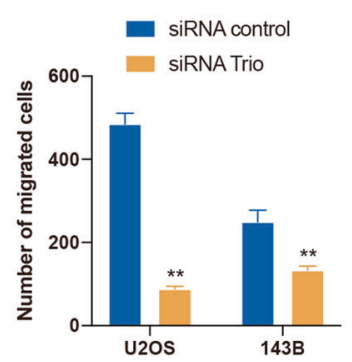

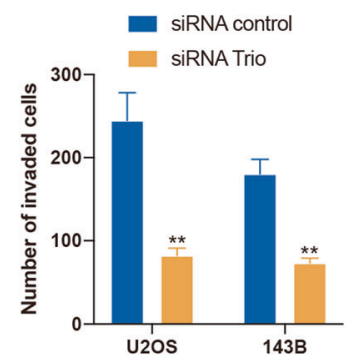

siRNA-Trio
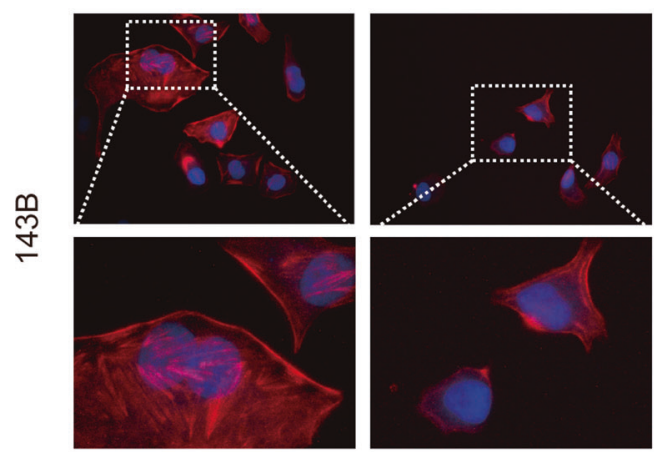

Fig. 3 Trio knockdown inhibits osteosarcoma cell migration and invasion, and effects actin cytoskeleton rearrangements. A and B Wound-healing assay was used to measure the migration capacity of U2OS and 143B cells. Representative images are shown (magnification at $\times 100$ ). C and D Transwell migration and Matrigel invasion assays were used to measure the migration and invasion ability of U2OS and $143 B$ cells. Representative images are shown (magnification at $\times 200$ ). E Cells of the siRNA-Trio group displayed more stress fibers and stable actin structures compared with the control group. Representative images are shown (magnification at $\times 400$ ). Data are shown as the mean \pm SD. ${ }^{*} p$ $<0.05,{ }^{* *} p<0.01$. Scale bars: $100 \mu \mathrm{m}$.

levels both exhibited an obvious increment after Trio was knocked down. Conversely, mesenchymal markers (N-cadherin, Vimentin) were down-regulated. Besides, as demonstrated in Fig. 4D, similar results were obtained by Immunofluorescence assay. In addition, to further characterize the effect of Trio on EMT, we examined the EMT-related transcription factors (MMP9, Snail), and their expression were also decreased after Trio knocked down (Fig. 4A-C). Collectively, Trio promoted OS progression in part through EMT.

\section{Trio knockdown promotes osteoblastic differentiation of OS} cells

Previous studies have shown that OS cells have incomplete osteoblast differentiation characteristics and loss of differentiation 
A

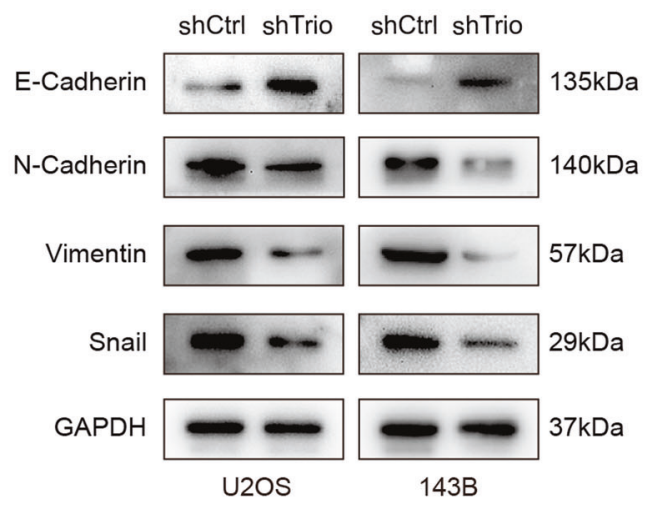

C
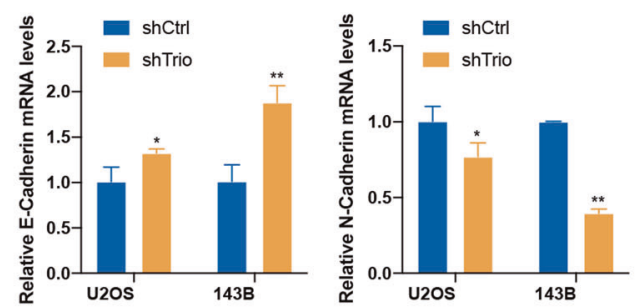

D
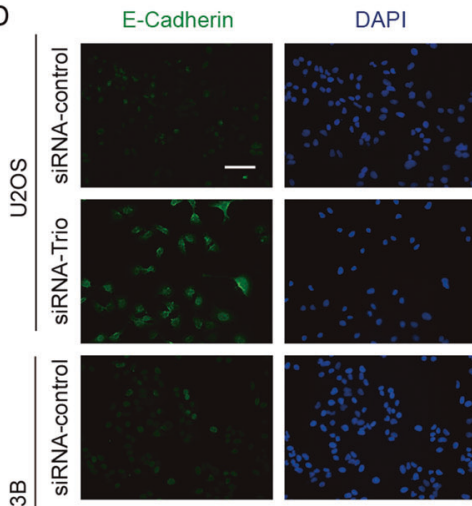

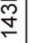
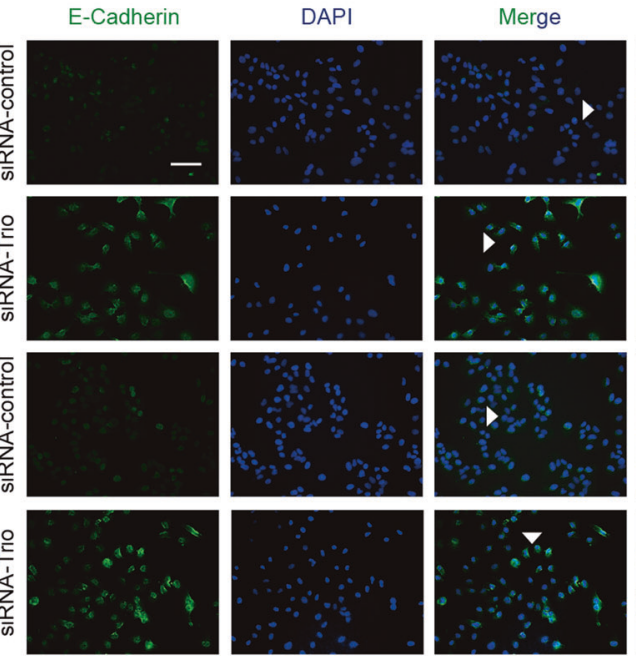
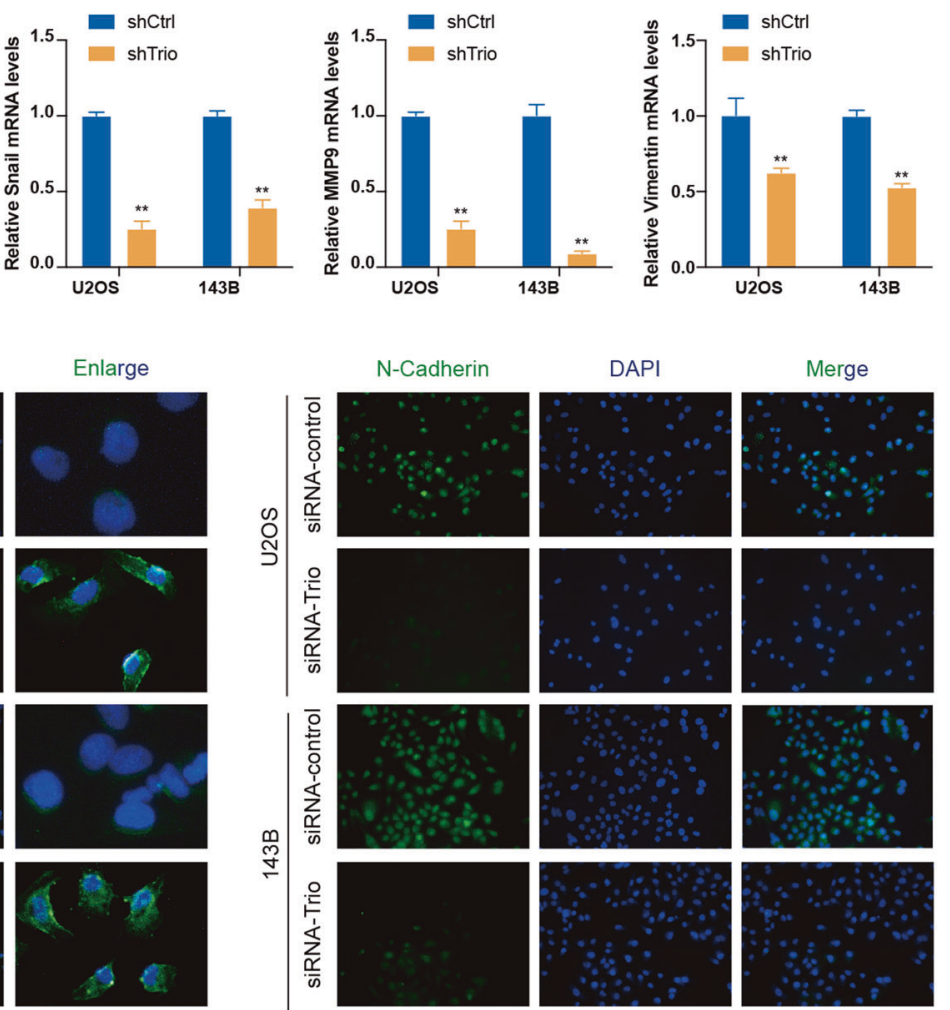

Fig. 4 Trio knockdown suppresses EMT in osteosarcoma cells. A and B EMT markers and Snail were measured by western blotting in U2OS and $143 \mathrm{~B}$ cells after transfection. C EMT markers and transcription factors (MMP9 and Snail) were measured by qRT-PCR. D U2OS and 143B cells were subjected to immunofluorescence with $\mathrm{E}$-Cadherin and $\mathrm{N}$-Cadherin antibodies. Local enlarged images showed the membrane localization of E-cad. Representative images are shown (magnification at $\times 200$ ). Data are shown as the mean \pm SD. ${ }^{*} p<0.05,{ }^{* *} p<0.01$. Scale bars: $100 \mu \mathrm{m}$.

is a remarkable feature of osteosarcoma [34-37]. OS is associated with mutations during the differentiation of mesenchymal stem cells into osteoblasts and osteogenic differentiation of OS cells hampers OS proliferation and progression [34, 38, 39]. U2OS and $143 \mathrm{~B}$ cells transfected with shCtrl or shTrio lentivirus stably were cultured in osteogenic media for 7 days (for ALP staining, western blot and real time PCR) or 14 days (for ARS staining). As shown in Fig. 5A-C, osteogenic differentiation markers (OPN, OCN) and osteogenic-related transcription factors (OSX, RUNX2) exhibited an upward trend both on transcriptional and protein levels after Trio knocked down. Furthermore, we performed ALP staining and ARS staining in vitro to directly observe the ALP activity and mineralization levels of cells (Fig. 5D-G). It is obvious that the osteogenic differentiation was induced though Trio deletion. In summary, Trio regulated OS progression by influencing osteogenic differentiation, which may provide us with a novel direction for the treatment of OS in the future.

\section{Trio knockdown suppresses tumor growth in vivo}

To gain a deeper understanding of Trio's role in OS, we built a tumor xenograft model. Four weeks-old BALB/C nude mice were chosen for experiments and injected with U2OS cells subcutaneously. During this period, the tumor volume was measured every other week (Fig. 6D). Seven weeks later, we observed that 
A

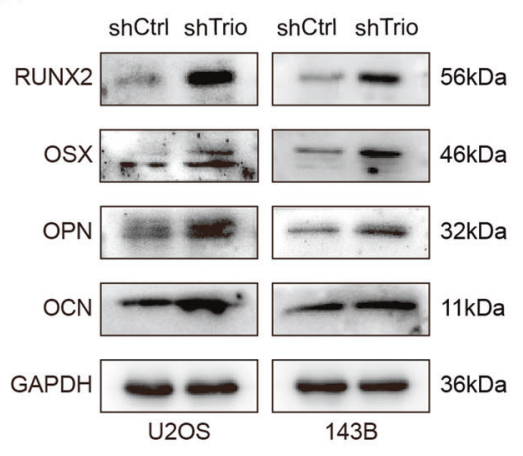

B
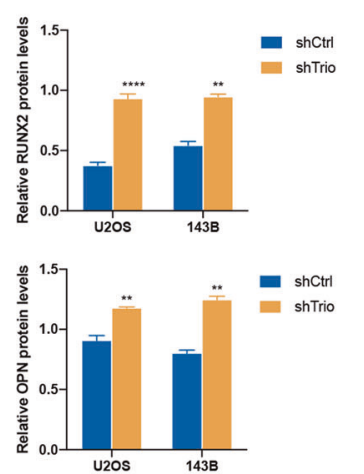
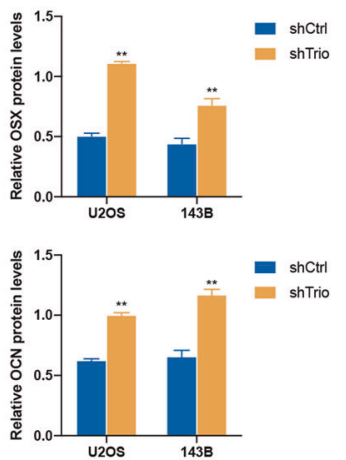

C
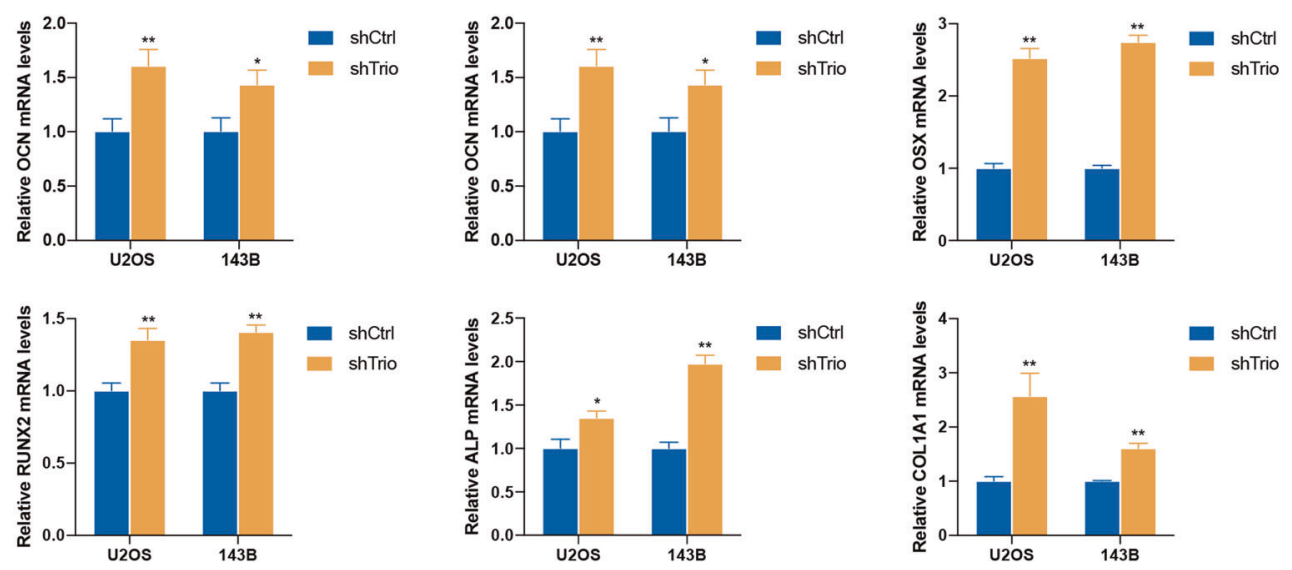

D

shTrio

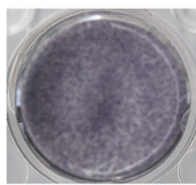

143B

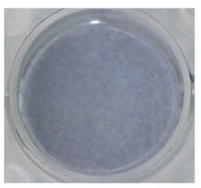

F
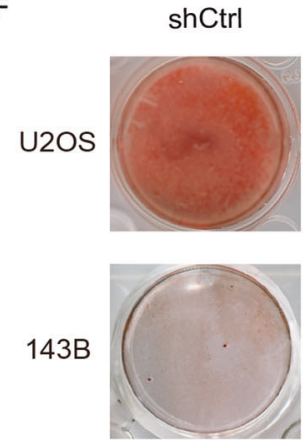

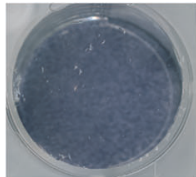

shTrio
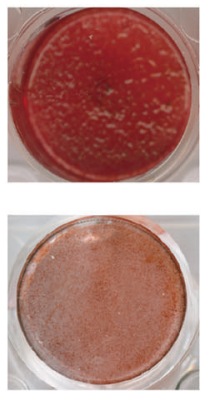

$\mathrm{E}$
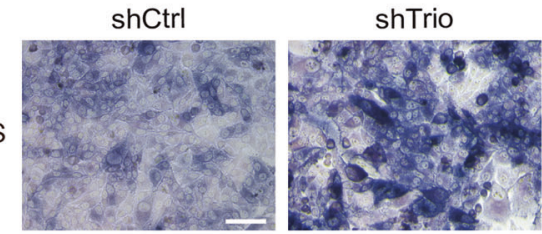

143B

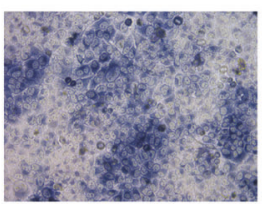

G
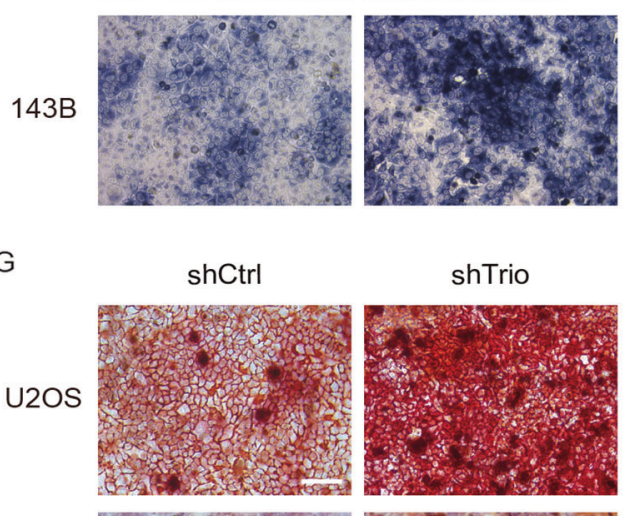

143B

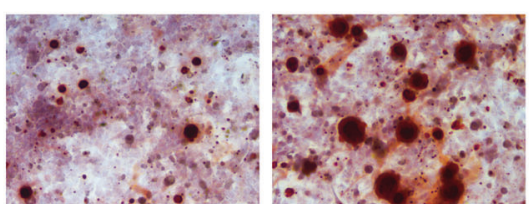

Fig. 5 Trio knockdown promotes osteoblastic differentiation of osteosarcoma cells. A and B osteogenic markers were measured by western blotting in U2OS and 143B cells after transfection. C osteogenic markers and transcription factors were measured by qRT-PCR. D, E $\mathrm{U} 2 \mathrm{OS}$ and $143 \mathrm{~B}$ cells were stained with the ALP kit. Representative images are shown (magnification at $\times 200$ ). F, G U2OS and $143 \mathrm{~B}$ cells were stained with ARS solution. Representative images are shown (magnification at 200x). Data are shown as the mean \pm SD. ${ }^{*} p<0.05,{ }^{* *} p<0.01$. Scale bars: $100 \mu \mathrm{m}$. 
A

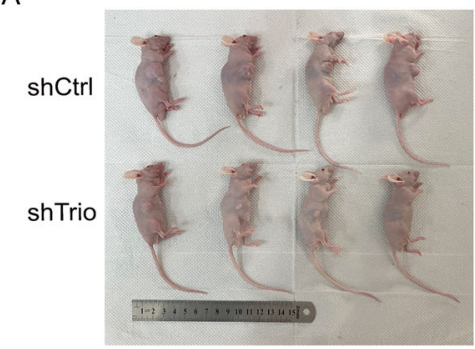

D

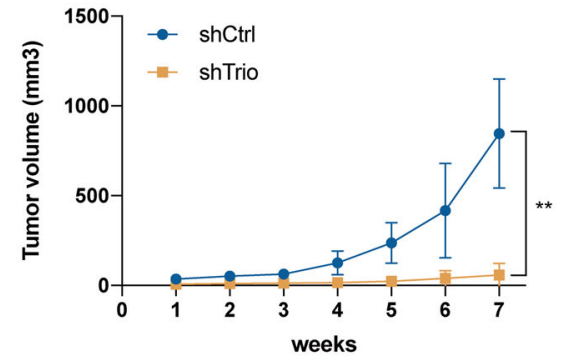

B

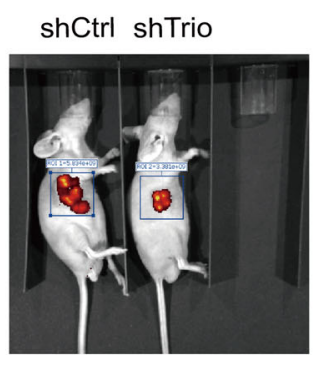

E
C

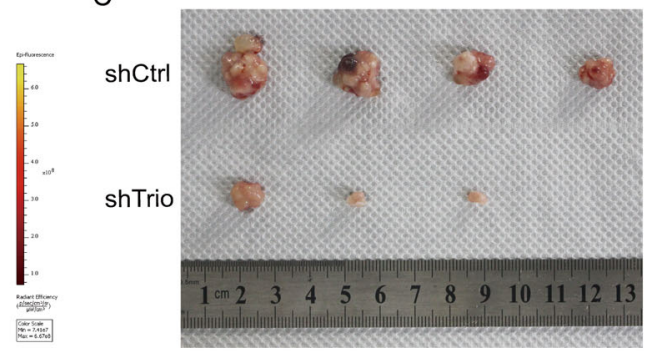

F
G

shCtrl

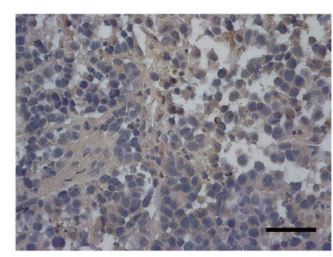

shTrio

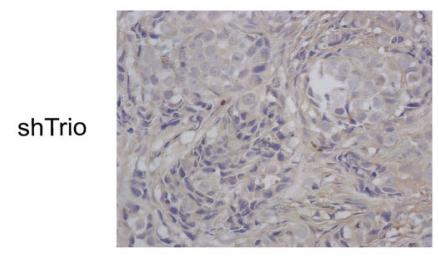

$\mathrm{H}$

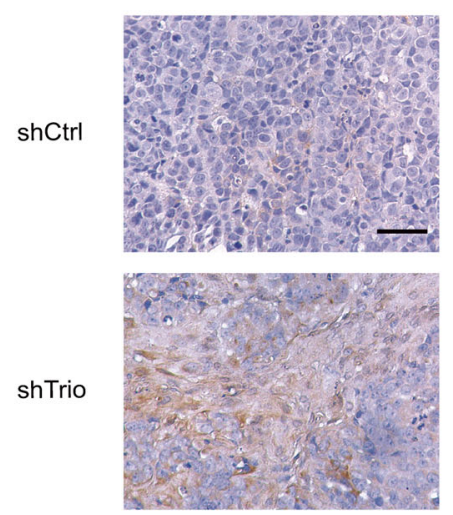

RUNX2

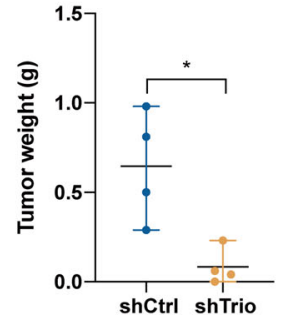

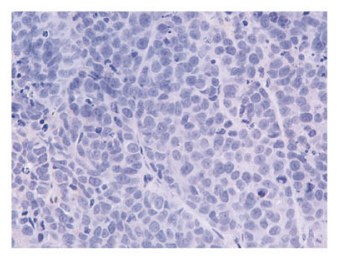

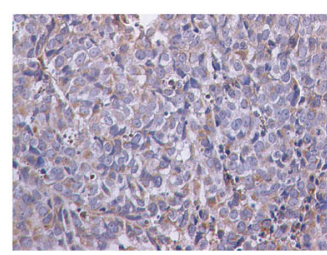

osx
E-cadherin
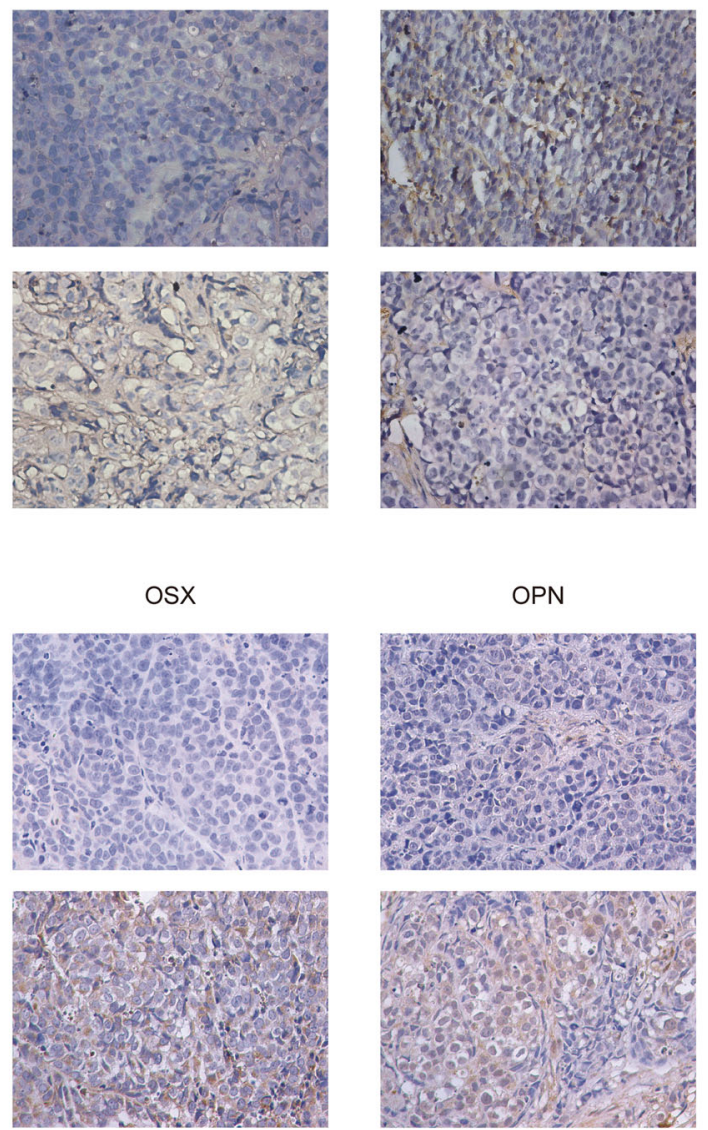

shCtrl

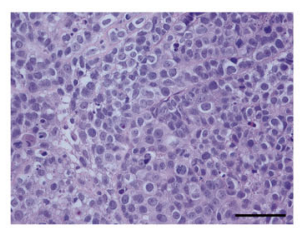

$\mathrm{N}$-cadherin
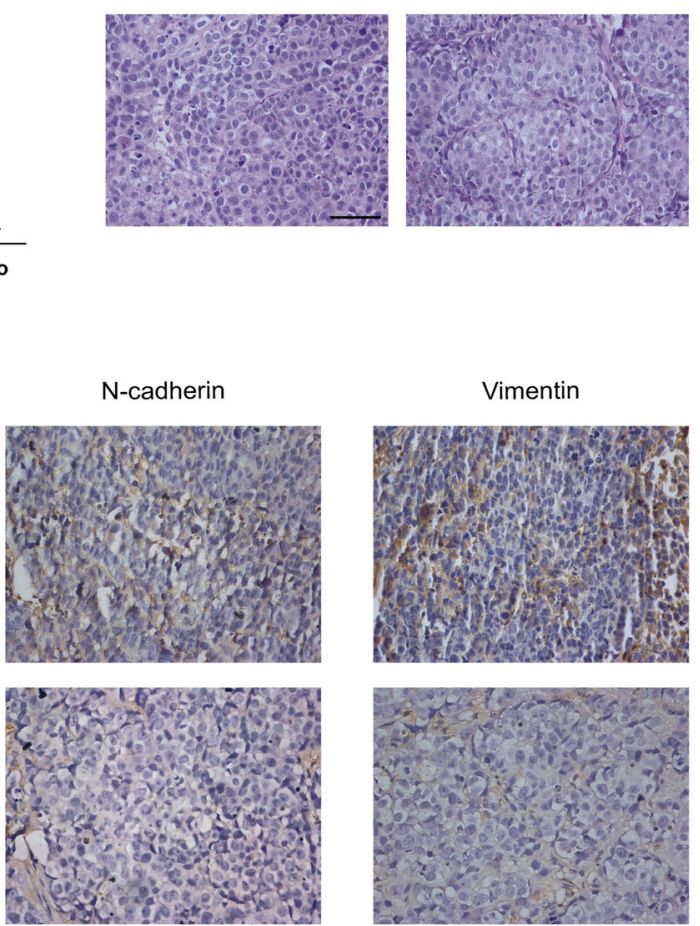

Fig. 6 Trio knockdown suppress tumor growth in vivo. A, B After 7 weeks, the photos of BALB/C nude mice were taken. C Tumors were removed and photographed. $\mathbf{D}$, E The volume and weight of tumor xenograft in nude mice were recorded. F-H The tumor tissues were detected by HE and IHC staining. Representative images are shown (magnification at $\times 400$ for IHC). Data are shown as the mean \pm SD. ${ }^{*} p<$ $0.05,{ }^{* *} p<0.01$. Scale bars: $50 \mu \mathrm{m}$. 
A

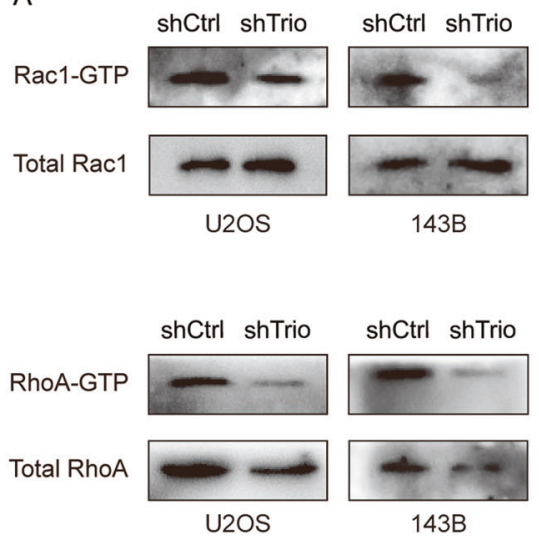

B

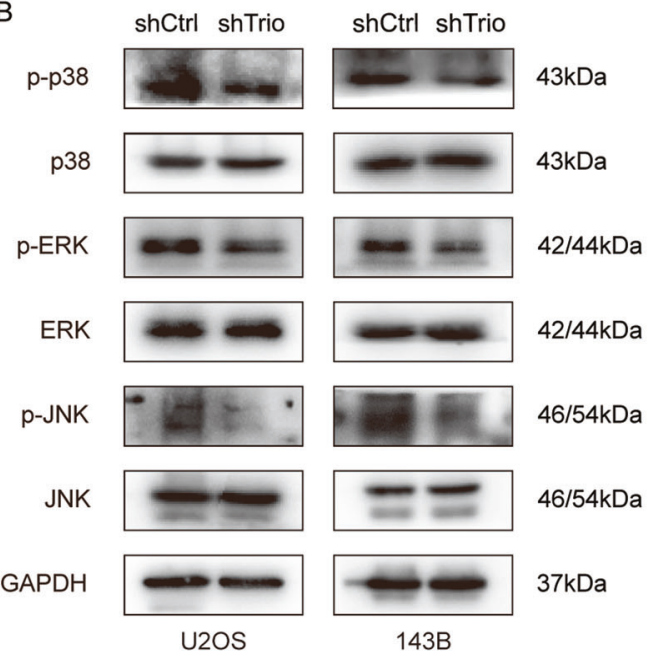

C
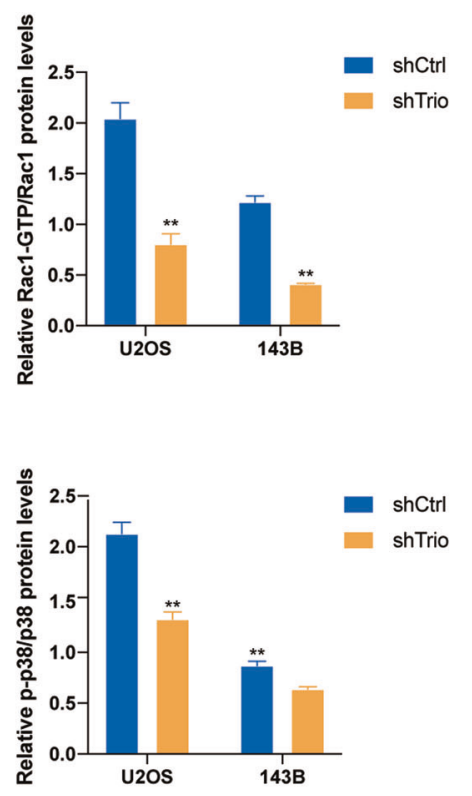
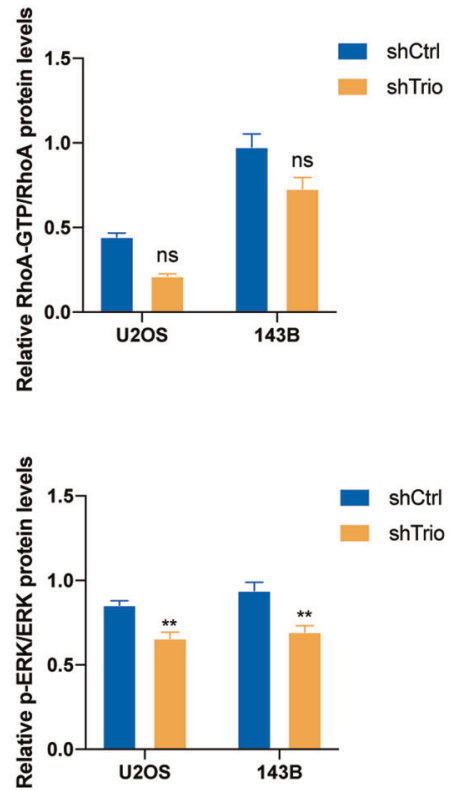

shTrio

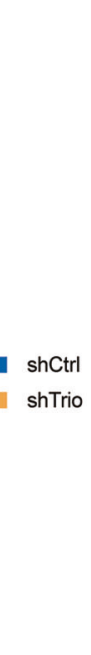

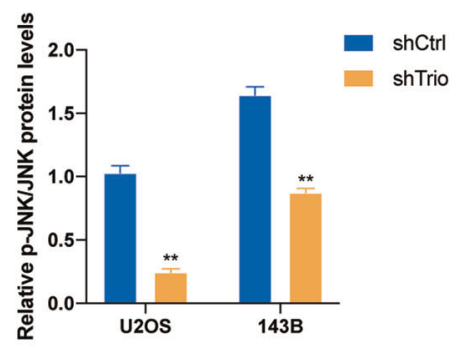

Fig. 7 Trio regulates the progression of osteosarcoma through Rac1 and RhoA. A GTP-bound forms of Rac1 and RhoA were measured by pull-down assay and western blot. B Classical members of the MAPK pathway were analyzed by western blot. C Quantitative analysis of the protein levels in (A) and (B). Data are shown as the mean \pm SD. ${ }^{*} p<0.05,{ }^{* *} p<0.01$.

the tumor exhibited a significantly decreased growth in vivo in the shTrio group through the IVIS Spectrum Imaging System (Fig. 6A, B). Subsequently, we took the tumors out and weight them. It is evident that the tumors weighed less (Fig. 6E) and the volume increased more slowly during tumor growth in the shTrio group (Fig. 6A, C, D). Additionally, we performed IHC and H\&E staining as shown in Fig. $6 \mathrm{~F}-\mathrm{H}$, which were in agreement with the results in vitro. In conclusion, Trio knockdown could impede the growth of tumors and promote osteoblastic differentiation of OS cells to some extent.

Trio regulates the progression of OS through Rac1 and RhoA Given the established role of Trio in OS, it is necessary to further explore its mechanism of action. Since Trio contains two GEF domains, we conceived whether Trio activated RhoGTPases via GEF. Accordingly, we conducted related studies. It was observed that the expression of total Rac1 remained unchanged after Trio was knocked down, but the active Rac1 decreased significantly (Fig. 7A, C). Unexpectedly, the total RhoA was significantly reduced, so was the active RhoA (Fig. 7A, C). This discrepancy had invited speculation regarding other regulation ways that Trio acted on RhoA. We considered the possibility that Trio may indirectly regulate RhoA-GTP by controlling the total RhoA.

There has been a number of studies indicating that the MAPK pathway was a downstream pathway of RhoGTPases and played a role in the process of osteogenic differentiation [36, 40-42], thus we pondered over whether it was also suitable for OS. Western bolt indicated that p-p38, p-JNK, p-ERK were all down-regulated in the shTrio group (Fig. 7B, C). In general, all results above revealed that Trio could regulate the MAPK pathway via Rac1 and RhoA to participate in EMT and osteogenic differentiation, eventually influencing the proliferation, migration, invasion, and growth of OS (Fig. 8).

\section{DISCUSSION}

Herein, we proved that Trio could be involved in promoting the progression of OS both in vitro and vivo for the first time. In addition, since OS cells originate from osteoblasts and several studies have pointed out that differentiation therapy may be a novel promising approach intended to restore normal programs of differentiation $[35,43]$. We examined whether Trio affected the osteogenic differentiation of OS cells. As a result, we revealed that Trio could inhibit OS's osteogenic differentiation both in vitro and vivo, supporting the notion above. However, it remains to be elucidated in more detail about the exact mechanism in the future.

A number of studies have put forward that Trio is instrumental in a variety of tumors [15, 19-21], however, there are few types of research on its regulatory mechanism. In this study, we outlined a 


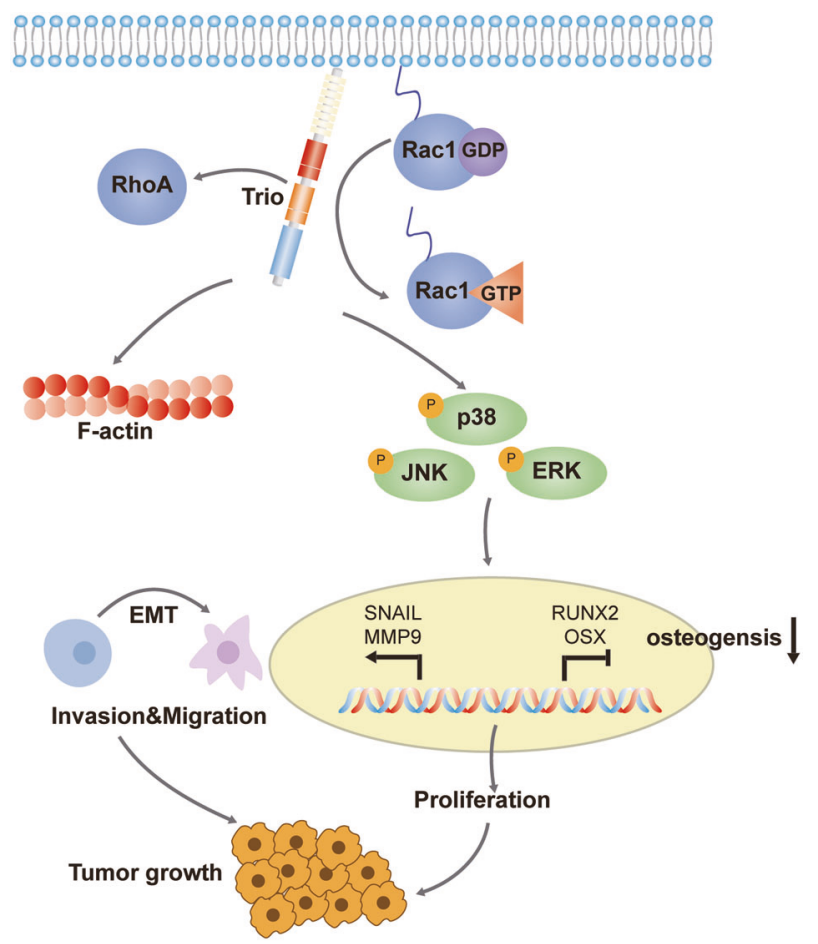

Fig. 8 Schematic diagram of mechanism on this research. Rho-GEF Trio promotes osteosarcoma progression and inhibits osteogenic differentiation through Rac1/RhoA-mediated MAPK pathway.

novel signaling pathway responsible for the effects of Trio on OS. Besides Trio, other RhoGEFs also have been reported to have an important function in cancer [44-46]. Accordingly, we considered the possibility that most RhoGEFs may play crucial roles in oncogenesis, which provided a new direction for further research. Moreover, Trio was thought to activate Rac1 and RhoA through distinct ways in our study. The discrepancies may be explained in part by the fact that Rac1 and RhoA display opposite behaviors and spatial localization in cell migration [44, 47]. Therefore, we postulated that there may be a balance between Rac1 and RhoA.

It is well known that the MAPK pathway plays a crucial role in osteogenic differentiation and tumor progression [48-50]. Furthermore, several studies have proved that the MAPK pathway is a downstream pathway of RhoGTPase [36, 40], but there are relatively few studies in OS to date. Thus, we explored whether this regulatory axis exists in OS. Eventually, we demonstrated that the Rac1/RhoA-p38/ERK/JNK axis did play a role in OS.

EMT is a typical biological process in tumor development [51]. In this process, cells will lose their cell polarity, cell-cell contact, and adhesion, then gain migratory and invasive abilities [52-54]. Studies have shown that RhoGTPase involves in EMT [55-59], in which RhoA promotes the formation of stress fibers, whereas Rac1 and $\mathrm{Cdc} 42$ promote the lamellipodia and filopodia formation $[53,60]$. For this reason, there was a hypothesis that Trio regulated EMT through Rac1/RhoA-p38/ERK/JNK pathway. To test this hypothesis, we performed some assays to confirm it.

In conclusion, we have found the Trio-Rac1/RhoA-p38/ERK/JNK regulatory axis which induced EMT and impeded osteogenic differentiation in OS cells, leading to the progression of OS and bone destruction eventually. This regulatory axis may serve as a therapeutic target in the prevention and treatment of OS in the future.

\section{DATA AVAILABILITY}

The data that support the findings of this study are available on request from the corresponding author.

\section{REFERENCES}

1. Smrke A, Anderson PM, Gulia A, Gennatas S, Huang PH, Jones RL. Future directions in the treatment of osteosarcoma. Cells. 2021;10:172.

2. Longhi A, Errani C, De Paolis M, Mercuri M, Bacci G. Primary bone osteosarcoma in the pediatric age: state of the art. Cancer Treat Rev. 2006;32:423-36.

3. McHugh JB, Thomas DG, Herman JM, Ray ME, Baker LH, Adsay NV, et al. Primary versus radiation-associated craniofacial osteosarcoma: biologic and clinicopathologic comparisons. Am Cancer Soc. 2006;107:554-62.

4. Otoukesh B, Boddouhi B, Moghtadaei M, Kaghazian P, Kaghazian M. Novel molecular insights and new therapeutic strategies in osteosarcoma. Cancer Cell Int. 2018;18:158.

5. Luetke A, Meyers PA, Lewis I, Juergens H. Osteosarcoma treatment-where do we stand? A state of the art review. Cancer Treat Rev. 2014;40:523-32.

6. Brookes M, Chan C, Baljer B, Wimalagunaratna S, Crowley T, Ragbir M. Surgical advances in osteosarcoma. Cancers. 2021;13:388

7. Belayneh R, Fourman M, Bhogal S, Weiss K. Update on osteosarcoma. Curr Oncol Rep. 2021;23:71.

8. Czarnecka A, Synoradzki K, Firlej W, Bartnik E, Sobczuk P, Fiedorowicz M, et al. Molecular biology of osteosarcoma. Cancers. 2020;12:2130.

9. Corre I, Verrecchia F, Crenn V, Redini F, Trichet V. The osteosarcoma microenvironment: a complex but targetable ecosystem. Cells. 2020;9:976.

10. Yang C, Tian Y, Zhao F, Chen Z, Su P, Li Y, et al. Bone microenvironment and osteosarcoma metastasis. Int J Mol Sci. 2020;21:6985.

11. Chen C, Xie L, Ren T, Huang Y, Xu J, Guo W. Immunotherapy for osteosarcoma: fundamental mechanism, rationale, and recent breakthroughs. Cancer Lett. 2021;500:1-10.

12. Reiner DJ, Lundquist EA. Small GTPases. WormBook. 2018;2018:1-65.

13. Hodge RG, Ridley AJ. Regulating Rho GTPases and their regulators. Nat Rev Mol Cell Biol. 2016;17:496-510.

14. O'Connor K, Chen M. Dynamic functions of RhoA in tumor cell migration and invasion. Small GTPases. 2013;4:141-7.

15. Schmidt S, Debant A. Function and regulation of the Rho guanine nucleotide exchange factor Trio. Small GTPases. 2014;5:e29769.

16. Pengelly RJ, Greville-Heygate S, Schmidt S, Seaby EG, Jabalameli MR, Mehta SG, et al. Mutations specific to the Rac-GEF domain of TRIO cause intellectual disability and microcephaly. J Med Genet. 2016;53:735-42.

17. Tao T, Sun J, Peng Y, Wang P, Chen X, Zhao W, et al. Distinct functions of Trio GEF domains in axon outgrowth of cerebellar granule neurons. J Genet Genom. 2019;46:87-96.

18. O'Brien SP, Seipel K, Medley QG, Bronson R, Segal R, Streuli M. Skeletal muscle deformity and neuronal disorder in Trio exchange factor-deficient mouse embryos. Proc Natl Acad Sci USA. 2000;97:12074-8.

19. Feng $X$, Degese MS, Iglesias-Bartolome $R$, Vaque JP, Molinolo AA, Rodrigues $M$, et al. Hippo-independent activation of YAP by the GNAQ uveal melanoma oncogene through a trio-regulated rho GTPase signaling circuitry. Cancer Cell. 2014;25:831-45.

20. Sonoshita $M$, Itatani $Y$, Kakizaki F, Sakimura $K$, Terashima $T$, Katsuyama $Y$, et al. Promotion of Colorectal Cancer Invasion and Metastasis through Activation of NOTCH-DAB1-ABL-RHOGEF Protein TRIO. Cancer Disco. 2015;5:198-211.

21. Bandekar SJ, Arang N, Tully ES, Tang BA, Barton BL, Li S, et al. Structure of the C-terminal guanine nucleotide exchange factor module of Trio in an autoinhibited conformation reveals its oncogenic potential. Sci Signal. 2019;12:2449.

22. Aspenstrom P. Activated Rho GTPases in cancer-the beginning of a new paradigm. Int J Mol Sci. 2018;19:3949.

23. O'Toole TE, Bialkowska K, Li X, Fox JE. Tiam1 is recruited to beta1-integrin complexes by 14-3-3zeta where it mediates integrin-induced Rac1 activation and motility. J Cell Physiol. 2011;226:2965-78.

24. Wang J, Zhang L, Qu R, Zhang L, Huang W. Rho A regulates epidermal growth factor-induced human osteosarcoma MG63 cell migration. Int J Mol Sci. 2018;19:1437.

25. Sahai E, Marshall CJ. RHO-GTPases and cancer. Nat Rev Cancer. 2002;2:133-42.

26. El-Naggar AM, Clarkson PW, Negri GL, Turgu B, Zhang F, Anglesio MS, et al. HACE1 is a potential tumor suppressor in osteosarcoma. Cell Death Dis. 2019;10:21.

27. Cooke M, Baker MJ, Kazanietz MG. Rac-GEF/Rac signaling and metastatic dissemination in lung cancer. Front Cell Dev Biol. 2020;8:118.

28. Zhang A, Yan T, Wang K, Huang Z, Liu J. PI3Kalpha isoform-dependent activation of RhoA regulates Wnt5a-induced osteosarcoma cell migration. Cancer Cell Int. 2017;17:27

29. Zhang JG, Zhou HM, Zhang X, Mu W, Hu JN, Liu GL, et al. Hypoxic induction of vasculogenic mimicry in hepatocellular carcinoma: role of HIF-1 alpha, RhoA/ ROCK and Rac1/PAK signaling. BMC Cancer. 2020;20:32.

30. Chen H, Guo S, Xia Y, Yuan L, Lu M, Zhou M, et al. The role of Rho-GEF Trio in regulating tooth root development through the p38 MAPK pathway. Exp Cell Res. 2018;372:158-67. 
31. Gu J, Yang Z, Yuan L, Guo S, Wang D, Zhao N, et al. Rho-GEF trio regulates osteoclast differentiation and function by Rac1/Cdc42. Exp Cell Res. 2020;396:112265.

32. Zhou M, Guo S, Yuan L, Zhang Y, Zhang M, Chen H, et al. Blockade of LGR4 inhibits proliferation and odonto/osteogenic differentiation of stem cells from apical papillae. J Mol Histol. 2017;48:389-401.

33. Thiery J. Epithelial-mesenchymal transitions in tumour progression. Nat Rev Cancer. 2002;2:442-54.

34. Quist T, Jin H, Zhu JF, Smith-Fry K, Capecchi MR, Jones KB. The impact of osteoblastic differentiation on osteosarcomagenesis in the mouse. Oncogene. 2015;34:4278-84.

35. Haydon RC, Luu HH, He TC. Osteosarcoma and osteoblastic differentiation: a new perspective on oncogenesis. Clin Orthop Relat Res. 2007;454:237-46.

36. Tang Q, Lu J, Zou C, Shao Y, Chen Y, Narala S, et al. CDH4 is a novel determinant of osteosarcoma tumorigenesis and metastasis. Oncogene. 2018;37:3617-30.

37. Tang N, Song WX, Luo J, Haydon RC, He TC. Osteosarcoma development and stem cell differentiation. Clin Orthop Relat Res. 2008;466:2114-30.

38. Liu C, Ma M, Zhang J, Gui S, Zhang X, Xue S. Galangin inhibits human osteosarcoma cells growth by inducing transforming growth factor-beta1-dependent osteogenic differentiation. Biomed Pharmacother. 2017;89:1415-21.

39. Lu Y, Lu D, Hu Y. GLP2 promotes directed differentiation from osteosarcoma cells to osteoblasts and inhibits growth of osteosarcoma cells. Mol Ther Nucleic Acids. 2018;10:292-303.

40. Shi D, Wu F, Mu S, Hu B, Zhong B, Gao F, et al. LncRNA AFAP1-AS1 promotes tumorigenesis and epithelial-mesenchymal transition of osteosarcoma through RhoC/ROCK1/p38MAPK/Twist1 signaling pathway. J Exp Clin Cancer Res. 2019;38:375.

41. Cardone RA, Bagorda A, Bellizzi A, Busco G, Guerra L, Paradiso A, et al. Protein kinase A gating of a pseudopodial-located RhoA/ROCK/p38/NHE1 signal module regulates invasion in breast cancer cell lines. Mol Biol Cell. 2005;16:3117-27.

42. Zhang Y, Dai Q, Zeng F, Liu H. MALAT1 promotes the proliferation and metastasis of osteosarcoma cells by activating the Rac1/JNK pathway via targeting MiR-509. Oncol Res. 2018.

43. Zhang N, Ying MD, Wu YP, Zhou ZH, Ye ZM, Li H, et al. Hyperoside, a flavonoid compound, inhibits proliferation and stimulates osteogenic differentiation of human osteosarcoma cells. PLoS ONE. 2014;9:e98973.

44. Guo XJ, Wang M, Jiang JX, Xie CC, Peng F, Li X, et al. Balanced Tiam1-Rac1 and RhoA drives proliferation and invasion of pancreatic cancer cells. Mol Cancer Res. 2013;11:230-9.

45. Izumi D, Toden S, Ureta E, Ishimoto $T$, Baba H, Goel A. TIAM1 promotes chemoresistance and tumor invasiveness in colorectal cancer. Cell Death Dis. 2019;10:267.

46. Liu CX. Epigenetically upregulated GEFT-derived invasion and metastasis of rhabdomyosarcoma via epithelial mesenchymal transition promoted by the Rac1/Cdc42-PAK signaling pathway. Ebiomedicine. 2021;50:122-134.

47. Nguyen LK, Kholodenko BN. von Kriegsheim A. Rac1 and RhoA: networks, loops and bistability. Small GTPases. 2018;9:316-21.

48. Lu KH, Chen PN, Hsieh YH, Lin CY, Cheng FY, Chiu PC, et al. 3-Hydroxyflavone inhibits human osteosarcoma U2OS and 143B cells metastasis by affecting EMT and repressing $\mathrm{u}-\mathrm{PA} / \mathrm{MMP}-2$ via FAK-Src to MEK/ERK and RhoA/MLC2 pathways and reduces 143B tumor growth in vivo. Food Chem Toxicol. 2016;97:177-86.

49. Liu JF, Chen PC, Chang TM, Hou CH. Monocyte Chemoattractant Protein-1 promotes cancer cell migration via c-Raf/MAPK/AP-1 pathway and MMP-9 production in osteosarcoma. J Exp Clin Cancer Res. 2020;39:254.

50. Wagner EF, Nebreda AR. Signal integration by JNK and p38 MAPK pathways in cancer development. Nat Rev Cancer. 2009;9:537-49.

51. De Craene B, Berx G. Regulatory networks defining EMT during cancer initiation and progression. Nat Rev Cancer. 2013;13:97-110.

52. Wang S, Zhang D, Han S, Gao P, Liu C, Li J, et al. Fibulin-3 promotes osteosarcoma invasion and metastasis by inducing epithelial to mesenchymal transition and activating the Wnt/beta-catenin signaling pathway. Sci Rep. 2017;7:6215.

53. Lamouille S, Xu J, Derynck R. Molecular mechanisms of epithelial-mesenchymal transition. Nat Rev Mol Cell Biol. 2014;15:178-96.

54. Yilmaz M, Christofori G. EMT, the cytoskeleton, and cancer cell invasion. Cancer Metastasis Rev. 2009;28:15-33.

55. Gulhati P, Bowen KA, Liu J, Stevens PD, Rychahou PG, Chen M, et al. mTORC1 and mTORC2 regulate EMT, motility, and metastasis of colorectal cancer via RhoA and Rac1 signaling pathways. Cancer Res. 2011;71:3246-56.

56. Yuan J, Chen L, Xiao J, Qi XK, Zhang J, Li X, et al. SHROOM2 inhibits tumor metastasis through RhoA-ROCK pathway-dependent and -independent mechanisms in nasopharyngeal carcinoma. Cell Death Dis. 2019;10:58.
57. Yu X, Wang D, Wang X, Sun S, Zhang Y, Wang S, et al. CXCL12/CXCR4 promotes inflammation-driven colorectal cancer progression through activation of RhoA signaling by sponging miR-133a-3p. J Exp Clin Cancer Res. 2019;38:32.

58. Liu C, Zhang L, Cui W, Du J, Li Z, Pang Y, et al. Epigenetically upregulated GEFTderived invasion and metastasis of rhabdomyosarcoma via epithelial mesenchymal transition promoted by the Rac1/Cdc42-PAK signalling pathway. EBioMedicine. 2019;50:122-34.

59. Ma H, Li T, Tao Z, Hai L, Tong L, Yi L, et al. NKCC1 promotes EMT-like process in GBM via RhoA and Rac1 signaling pathways. J Cell Physiol. 2019;234:1630-42.

60. Narumiya S, Tanji M, Ishizaki T. Rho signaling, ROCK and mDia1, in transformation, metastasis and invasion. Cancer Metastasis Rev. 2009;28:65-76.

\section{ACKNOWLEDGEMENTS}

This work was supported by the National Natural Science Foundation of China (82170911), Key Research Program in Jiangsu Province-Social Development Project (BE2021724), Postgraduate Research \& Practice Innovation Program of Jiangsu Province (SJCX20_0472) and a project funded by the Priority Academic Program Development of Jiangsu Higher Education Institutions (PAPD, 2018-87).

\section{AUTHOR CONTRIBUTIONS}

J.M. performed study concept and design; J.W. and L.Y. conducted the experiment, provided acquisition, analysis and interpretation of data, and statistical analysis; X.X., Y.Z., and L.H. assisted with animal studies; J.W. wrote the manuscript; J.M. reviewed the paper and provided technical and material support; J.W. and Y.M. revised the paper. All authors read and approved the final paper.

\section{ETHICS STATEMENT}

Animal experiments above were conducted according to the protocols approved by the Ethics Committee of Nanjing Medical University (Permit number: IACUC2103023).

\section{COMPETING INTERESTS}

The authors declare no competing interests.

\section{ADDITIONAL INFORMATION}

Supplementary information The online version contains supplementary material available at https://doi.org/10.1038/s41419-021-04448-3.

Correspondence and requests for materials should be addressed to Junqing Ma.

Reprints and permission information is available at http://www.nature.com/ reprints

Publisher's note Springer Nature remains neutral with regard to jurisdictional claims in published maps and institutional affiliations.

pen Access This article is licensed under a Creative Commons Attribution 4.0 International License, which permits use, sharing, adaptation, distribution and reproduction in any medium or format, as long as you give appropriate credit to the original author(s) and the source, provide a link to the Creative Commons license, and indicate if changes were made. The images or other third party material in this article are included in the article's Creative Commons license, unless indicated otherwise in a credit line to the material. If material is not included in the article's Creative Commons license and your intended use is not permitted by statutory regulation or exceeds the permitted use, you will need to obtain permission directly from the copyright holder. To view a copy of this license, visit http://creativecommons. org/licenses/by/4.0/.

(c) The Author(s) 2021 